\title{
Cerebral Malaria: Mechanisms of Brain Injury and Strategies for Improved Neurocognitive Outcome
}

\author{
RICHARD IDRO, KEVIN MARSH, CHANDY C. JOHN, AND CHARLES R. J. NEWTON
}

\begin{abstract}
Department of Paediatrics and Child Health [R.I.], Mulago Hospital, Makerere University School of Medicine, Kampala, Uganda; Kenya Medical Research Institute and the Wellcome Trust Centre for Geographic Medicine Research-Coast [R.I., K.M., C.R.J.N.], Kilifi, Kenya; Centre for Clinical Vaccinology and Tropical Medicine [K.M.], University of Oxford, Oxford OX3 7LJ, United Kingdom; Department of Pediatrics [C.C.J], University of Minnesota, Minneapolis, Minnesota 55455; Clinical Research Unit [C.R.J.N], London School of Hygiene and Tropical Medicine, London WC1E 7HT, United Kingdom; Neurosciences Unit [C.R.J.N], UCL-Institute of Child Health, London WClN 1EH, United Kingdom
\end{abstract}

\begin{abstract}
Cerebral malaria is the most severe neurological complication of infection with Plasmodium falciparum. With $>575,000$ cases annually, children in sub-Saharan Africa are the most affected. Surviving patients have an increased risk of neurological and cognitive deficits, behavioral difficulties, and epilepsy making cerebral malaria a leading cause of childhood neurodisability in the region. The pathogenesis of neurocognitive sequelae is poorly understood: coma develops through multiple mechanisms and there may be several mechanisms of brain injury. It is unclear how an intravascular parasite causes such brain injury. Understanding these mechanisms is important to develop appropriate neuroprotective interventions. This article examines possible mechanisms of brain injury in cerebral malaria, relating this to the pathogenesis of the disease, and explores prospects for improved neurocognitive outcome. (Pediatr Res 68: 267-274, 2010)
\end{abstract}

$\mathrm{C}$ erebral malaria is the most severe neurological complication of infection with Plasmodium falciparum malaria. It is a clinical syndrome characterized by coma and asexual forms of the parasite on peripheral blood smears. Mortality is high and some surviving patients sustain brain injury that manifest as long-term neurocognitive impairments. In this article, we review studies that have provided current understanding of the pathogenesis of brain injury and explore prospects for neuroprotection and improved outcome.

\section{Epidemiology}

Falciparum malaria is a leading cause of ill health, neurodisability, and death in tropical countries. Although $40 \%$ of the world's population is at risk, most transmission occurs in subSaharan Africa, where children younger than $5 \mathrm{y}$ are the most affected and the incidence of disease declines in older children with increasing immunity. In South-East Asia, malaria occurs more commonly in adults but the clinical features are different (1).

Received June 17, 2010; accepted June 20, 2010.

Correspondence: Richard Idro, Ph.D., Department of Paediatrics and Child Health, Mulago Hospital, Makerere University School of Medicine, P.O. Box 7072, Kampala, Uganda; e-mail: ridro1@gmail.com

Supported by the Wellcome Trust (R.I., K.M., and C.R.J.N.) and NIH (C.C.J.).
Every year, there are $>500$ million clinical cases. One percent of symptomatic infections may become complicated and develop into severe malaria. Severe malaria may manifest as anemia, hypoglycemia, metabolic acidosis, repeated seizures, coma, or multiple organ failure and is estimated to cause $>1$ million deaths annually (1). Cerebral malaria is the most severe neurological manifestation of severe malaria. With an incidence of $1,120 / 100,000 / y$ in the endemic areas of Africa, children in this region bear the brunt. Peak incidence is in preschool children and at a minimum, 575,000 children in Africa develop cerebral malaria annually (2). However, recent reports suggest that the incidence of severe malaria is on the decline $(3,4)$.

\section{Clinical Features}

The clinical features of cerebral malaria have been reviewed extensively $(5,6)$. In this article, we highlight some of the main features.

The World Health Organization defines cerebral malaria as a clinical syndrome characterized by coma at least $1 \mathrm{~h}$ after termination of a seizure or correction of hypoglycemia, asexual forms of Plasmodium falciparum parasites on peripheral blood smears, and no other cause to explain the coma (7). In practice, this definition is nonspecific. Patients in whom coma is caused by other encephalopathies (e.g. viral encephalitis, poisoning, and metabolic disease) or previously unrecognized neurological abnormalities but have incidental parasitemia (a common phenomenon in malaria endemic areas) may be included. Thus, in a postmortem study of Malawian children dying with a clinical diagnosis of cerebral malaria, $24 \%$ had other causes of death (8). This lack of specificity is problematic for clinical and pathogenesis studies. The increased specificity accorded by recent descriptions of retinal changes in cerebral malaria should address this issue (9).

Abbreviations: BBB, blood brain barrier; CSF, cerebrospinal fluid; EMPs, endothelial microparticles; PfEPM-1, Plasmodium falciparum erythrocyte membrane protein-1; pRBCs, parasitized red blood cells; TBI, traumatic brain injury 
Table 1. Neurocognitive sequel of cerebral malaria

\begin{tabular}{|c|c|c|}
\hline Type of sequel & Sequel on discharge & Long-term sequel \\
\hline Motor & $\begin{array}{l}\text { Spasticity (hemiplegia, quadriparesis, or quadriplegia), } \\
\text { cranial nerve palsies, and central hypotonia }\end{array}$ & $\begin{array}{l}\text { Spasticity (hemiplegia, quadriparesis, or quadriplegia) } \\
\text { and cranial palsies. Central hypotonia mostly resolves }\end{array}$ \\
\hline Movement disorders & Ataxia, tremors, and dystonia & Dystonia. Ataxia and tremors resolve \\
\hline Visual impairment & Blindness and milder degrees of visual impairment & Most visual impairment resolves \\
\hline $\begin{array}{l}\text { Speech and language } \\
\text { impairments }\end{array}$ & Aphasia & $\begin{array}{l}\text { Aphasia, impairments in pragmatics (use of language), } \\
\text { receptive and expressive language, word finding, content, } \\
\text { vocabulary, and phonology }\end{array}$ \\
\hline Cognitive deficits & $\begin{array}{l}\text { Impairments in working memory, attention, and } \\
\text { learning }\end{array}$ & $\begin{array}{l}\text { Impairments in attention, executive function and working } \\
\text { memory, nonverbal functioning, and learning }\end{array}$ \\
\hline Epilepsy & $\begin{array}{l}\text { Generalized tonic clonic seizures and secondarily } \\
\text { generalized seizures }\end{array}$ & $\begin{array}{l}\text { Mostly generalized tonic clonic seizures and secondarily } \\
\text { generalized seizures }\end{array}$ \\
\hline $\begin{array}{l}\text { Behavior difficulties and } \\
\text { neuropsychiatric sequel }\end{array}$ & & $\begin{array}{l}\text { Attention difficulties, impulsiveness and hyperactivity, conduct } \\
\text { disorders, self-injurious and destructive behavior in children, } \\
\text { and the postmalaria neurological syndrome (acute psychosis, } \\
\text { inappropriate speech and behavior, hallucinations, catatonia, } \\
\text { and convulsions) in adults }\end{array}$ \\
\hline
\end{tabular}

The clinical hallmark of cerebral malaria is coma. This is thought to be caused by parasitized red blood cells (pRBCs) sequestered in cerebral microcirculation, but other authors attribute the impaired consciousness to metabolic factors and inflammatory mediators (10). In African children, coma develops suddenly with seizure onset often after $1-3 \mathrm{~d}$ of fever. A few children develop coma after progressive weakness and prostration. Brain swelling, intracranial hypertension, retinal changes (hemorrhages, peripheral and macular whitening, vessel discoloration, and/or papilledema) and brainstem signs (abnormalities in posture, pupil size and reaction, ocular movements, or abnormal respiratory patterns) are commonly observed. Other systemic complications such as anemia, metabolic acidosis, electrolyte imbalance, hyperpyrexia or hypoglycemia, and shock are commonly present. The prognosis is grave in deeply comatose patients with severe metabolic acidosis, shock, hypoglycemia, and repeated seizures.

In adults, cerebral malaria is part of a multiorgan disease. Patients develop fever, headache, body ache, and, progressively, delirium and coma. Compared with African children, seizures, papilledema, and retinal changes are less common and coma resolution is slower. Anemia, hemoglobinuria, jaundice, shock, renal failure, lactic acidosis, abnormal bleeding, pulmonary edema, and adult respiratory distress syndrome may develop. Some develop cortical infarcts and cerebral venous or dural sinus thrombosis as part of a disordered coagulation. Bacterial coinfection may be observed, particularly in those with shock, and accounts for the majority of late deaths $(5,6)$.

\section{Outcome}

Without treatment, cerebral malaria is invariably fatal. In children, parenteral antimalarials (cinchonoids or artemisinin derivatives) are indicated, but even with this treatment, 15$20 \%$ die. However, in adults, mortality was lower if patients were treated with i.v. artesunate (11). This treatment is currently being evaluated in African children.

Earlier studies suggested that surviving patients fully recover (12), but over the past $20 \mathrm{y}$, it became clear that many children sustain significant brain injury; $11 \%$ are discharged with gross neurological deficits $(13,14)$. Although some gross deficits such as blindness, ataxia, and central hypotonia improve with time (15), 25\% have long-term impairments especially cognition, motor function, or behavior impairments and epilepsy develops in 10\% (15-18), Table 1 . The prevalence $(<5 \%)$ and pattern of neurological deficits are different in adults. Thus, other than causing thousands of deaths, cerebral malaria is now considered a leading cause of neurodisability in African children. The main risk factors include repeated seizures, deep and prolonged coma, intracranial hypertension, and hypoglycemia.

\section{MECHANISMS OF BRAIN INJURY IN CEREBRAL MALARIA}

The mechanisms of neural injury in cerebral malaria are poorly understood. Although the pathogenesis of cerebral malaria is incompletely understood, an insight into it can provide leads to the mechanisms of brain injury. In addition, descriptions of the prognostic factors for neurocognitive sequelae and postmortem studies have provided some understanding. However, three observations raise the following questions: 1) how does a largely intravascular parasite cause so much neuronal dysfunction? 2) despite the large number of parasites in the brain of most patients, why is coma so rapidly reversible with treatment and with very little demonstrable tissue necrosis? and 3) despite similar presentation, why do some children have a poor neurological outcome while others improve with hardly any deficits?

A fundamental problem in assessment of cerebral malaria pathogenesis is the relative paucity of CNS pathologic or physiologic data in humans. Because invasive testing of brain tissue is not safe, available data are largely from autopsy studies. However, these studies are limited in sample size and cannot address potential differences in survivors when compared with patients who die. Given this limitation, the majority of pathogenesis studies have been conducted in animal models, particularly murine models involving C57BL/6 or CBA mice infected with $P$. berghei ANKA. Although they have provided a wealth of information, important differences in what is known of pathogenesis in humans compared with 
mice suggest that direct extrapolation of findings to human cerebral malaria may not be appropriate (19).

\section{Parasite Sequestration in the Brain}

Parasite sequestration in cerebral microvasculature is thought to be a central factor in pathogenesis and the resulting pathophysiological changes in tissue around the sequestered parasites, which may explain why an intravascular parasite may cause neural dysfunction and why some patients may have a poor outcome. Clearly, there are other factors because sequestration is also observed in patients dying of other complications of falciparum malaria (20).

Sequestration results from adherence of pRBCs to the endothelial lining (cytoadherence) using parasite-derived proteins exposed on erythrocyte surface (21). A group of parasite antigens including Plasmodium falciparum erythrocyte membrane protein-1 (PfEMP-1) mediate binding to host receptors of which intercellular adhesion molecule-1 (ICAM-1) is the most important and whose expression is up-regulated in areas adjacent to sequestered parasites. The sequestered parasite mass is further increased when adherent erythrocytes agglutinate with other $\mathrm{pRBCs}$, form rosettes with nonparasitized erythrocytes, or use platelet-mediated clumping to bind to each other. Sequestration impairs perfusion and may aggravate coma through hypoxia. Furthermore, the ability of pRBCs to deform and pass through the microvasculature is decreased (22). Therefore, hypoxia and inadequate tissue perfusion may be major pathophysiological events. Although a critical reduction in metabolite supply (oxygen and glucose) may occur, in the majority of children, significant neural tissue necrosis is unlikely because with specific antimalarial treatment, coma is rapidly reversible. However, in the presence of increased metabolic demand such as during seizures and fever, the risk of neural injury is higher and may be worse if the patient is hypoglycemic (23) or if blood flow is further compromised by intracranial hypertension (24).

\section{Cytokines, Chemokines, and Excitotoxicity}

Cytokines and chemokines play a complex role in pathogenesis and have both protective and harmful effects. Parasite antigens released at schizogony trigger the release of both proand antiinflammatory cytokines. Although the balance between these mediators is critical for parasite control, their role in pathogenesis of the neuronal damage is unclear. TNF, the most extensively studied cytokine in cerebral malaria, upregulates ICAM-1 expression on the cerebral vascular endothelium increasing the cytoadhesion of pRBCs. Near areas of sequestration, there is increased local synthesis. The timing of this is important because early in disease, TNF may be protective but prolonged high levels contribute to complications (25). TNF is also involved in regulating synaptic transmission (strength, scaling, and long-term potentiation) (10). Thus, cytokine-mediated synaptic changes may contribute to the syndrome of cerebral malaria. Despite the prominence of TNF in pathogenesis, pentoxifylline, which decreases macrophage TNF production $(26,27)$ and MAb to TNF (28), failed to decrease mortality.
Several other cytokines and chemokines are important, and in particular, interleukin (IL)-1b, IL-6, and IL-10 (29), but low levels of the chemokine RANTES are independently associated with mortality (30). The role of NO is controversial. The association between NO activity and inducible NO synthase with pathogenesis has been inconsistent $(31,32)$. NO is involved in host defense, maintaining vascular status, and neurotransmission and is thought to be an effector for TNF. It is suggested that inflammatory cytokines up-regulate inducible NO synthase in brain endothelial cells leading to increased NO production. NO can cross the blood brain barrier (BBB), diffuse into brain tissue, and interfere with neurotransmission and therefore may partly be responsible for the reversible coma (33).

Other inflammatory products such as the metabolites of the kynurenine pathway-quinolinic and kynurenic acid-may also be important in pathogenesis. Quinolinic acid is a NMDA receptor agonist and an excitotoxin. It causes seizures in animal models of brain disease, whereas kynurenic acid is an antagonist and is generally thought of as neuroprotective. Excitation by quinolinic acid may contribute to convulsions in cerebral malaria. In children, there are graded increases in cerebrospinal fluid (CSF) concentration across outcome groups of increasing severity (34) although in adults, increased levels were associated with impaired renal function (35). Because of the role of NMDA receptors in modulating neurotransmission and as agonists, high levels of quinolinic acid may have long-term deleterious effects on cognitive function.

\section{Endothelial Injury, Apoptosis, BBB Dysfunction, and Intracranial Hypertension}

Cytoadherence of $\mathrm{pRBCs}$ to the endothelium initiates a cascade of events beginning with the transcription of genes involved in inflammation, cell-to-cell signaling, and signal transduction, which result in endothelial activation, release of endothelial microparticles (EMPs), and apoptosis of host cells (36). There is widespread endothelial activation in vessels containing pRBCs, and compared with other complications of falciparum malaria, significant increases in circulating EMPs are seen in patients in coma (37). In addition, interactions between pRBCs and platelets (which produce platelet microparticles) cause further injury to endothelial cells through a direct cytotoxic effect (38). Repair of the injured endothelium is also impaired as there is failure to mobilize sufficient circulating endothelial progenitor cells (39), and plasma levels of endothelial regulators, angiopoietin-1 and angiopoietin-2, are altered (40).

In murine models, apoptosis is first observed in endothelial cells and then in neurons and glia (41); the stimulus being contact of pRBCs with the endothelium (42) (Fig. 1). There is accumulation of activated/effector CD8 lymphocytes. Apoptosis may be induced through a perforin-dependent process, because cerebral symptoms are not seen in perforin-deficient models but only in wild forms that show high increases in perforin mRNA (43). Four patterns of axonal injury have been described: single axons, diffuse or more focal parenchymal 


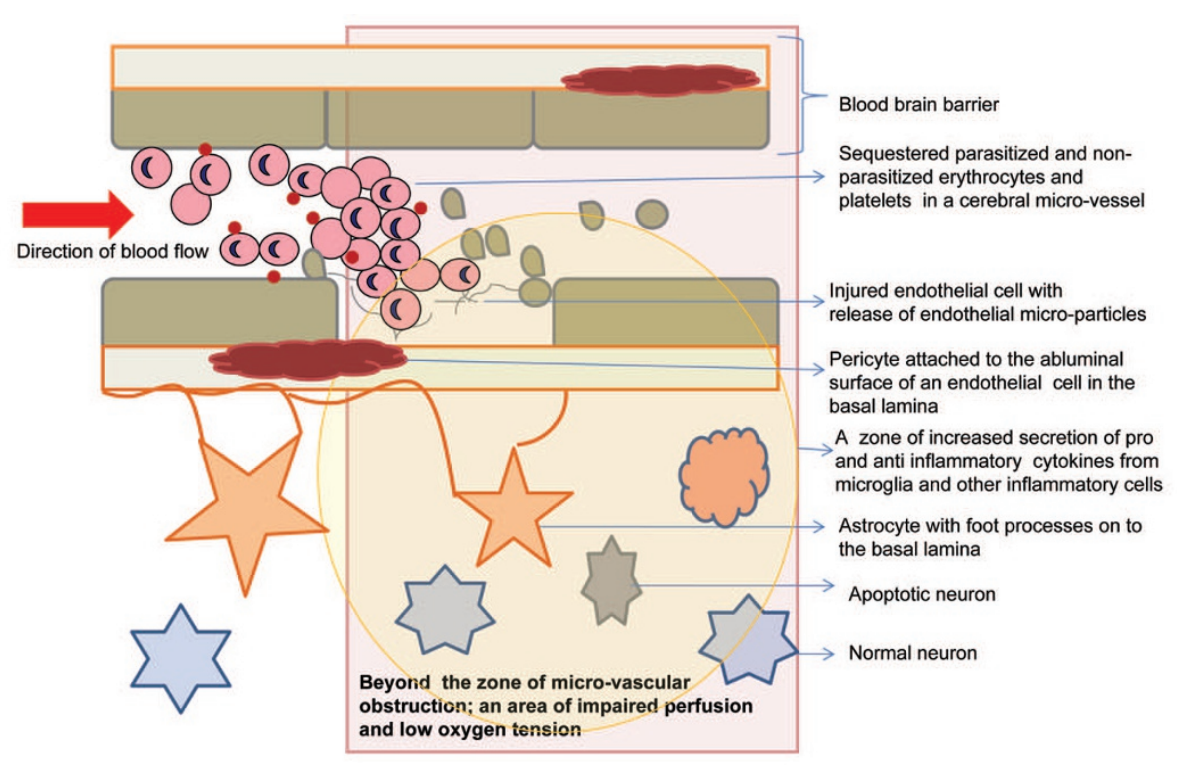

Figure 1. Changes in and around a cerebral microvessel with sequestered Plasmodium falciparum parasites. A schematic diagram showing changes in and around a cerebral vessel with sequestration of pRBCs. Cytoadherence of parasitized erythrocytes to the endothelial cell lining and sequestration of parasitized and nonparasitized cells in the cerebral capillary or postcapillary venule initiates an inflammatory process, endothelial activation, release of EMPs, and apoptosis in the exposed area. At the site of cytoadherence, the BBB is possibly disrupted, and there is an increased inflammatory response in the perivascular area with an increased release of proinflammatory cytokines. patches and neuronal cell bodies (44), and axonal injury correlated with plasma lactate and depth of coma. Axons in children seem to be more susceptible to injury because the median CSF microtubule-associated protein tau level is 3-fold greater than in adults (45). The increased susceptibility to injury may explain the higher prevalence of sequelae in children.

Perivascular macrophages around vessels with parasites express receptors such as sialoadhesin normally present only if there has been contact with plasma proteins (46). Although disruptions at sites of sequestration can expose neurons to plasma proteins, significant leakage of plasma proteins into perivascular spaces has not been seen (47). Despite this, intracranial hypertension is common in African children; up to $40 \%$ of children with deep coma have brain swelling on computerized tomography scans (48). BBB dysfunction may contribute to the hypertension, although increased cerebral volume could be caused by sequestration and increased cerebral blood flow from seizures, hyperthermia, or anemia.

Intracranial hypertension reduces cerebral perfusion pressure, nutrient and oxygen delivery and can lead to global ischemic injury, herniation, brainstem compression, and death $(24,49)$. Ischemic injury is seen on acute computerized tomography, and pattern of injury is consistent with a critical reduction in perfusion pressure (48). The convalescent scans in these patients show cerebral atrophy. Many children with severe hypertension are discharged with spastic quadriplegia and, subsequently, severe learning disability (24).

\section{Cerebral Blood Flow and Perfusion}

Patients with cerebral malaria have an increased cerebral blood flow. This increase is probably an adaptive response to high a metabolic demand to match oxygen and nutrient delivery to requirements because jugular bulb venous oxygen saturation remains within normal (50). However, recent studies of the retina have provided evidence for decreased local perfusion $(51,52)$. In the eye, multiple discrete areas (100$1000 \mu \mathrm{m})$ of retinal whitening are observed in most children with cerebral malaria. These areas have impaired capillary perfusion on fluorescein angiography (51), Figure 2. Physiologically, reduced local perfusion is associated with an abnormal electroretinograph (52). If the retina mirrors events in the brain, similar obstruction may be present in the brain, and coma in cerebral malaria may partly be a result of underperfusion in multiple but small areas of the brain. Because the patches of brain affected are small, with early treatment and rapid relief of obstruction, there is minimal tissue necrosis and early restoration of perfusion may explain the near complete recovery of gross neurological function in the majority of patients. However, exposure to hypoxia still leaves many children with subtle (e.g. cognitive) deficits. In those who die or develop severe brain injury, the sequestered mass may be higher, blood flow obstruction not readily reversed, and hypoxic and ischemic injury more widespread (53).

Regional blood flow may also be altered. In a transcranial Doppler study, sonographic abnormalities were associated with lateralizing deficits in six of 11 children who developed severe functional deficits on recovery (54), whereas in patients with severe intracranial hypertension, a linear relationship between cerebral perfusion pressure and blood flow velocity was observed suggesting that autoregulation was impaired. In addition, sonographic features suggesting progressive intracranial hypertension were seen in some who later died.

\section{Seizures}

Plasmodium falciparum is epileptogenic, and the risk of seizures increases with parasitemia (55). Seizures are a common feature of childhood cerebral malaria; $>80 \%$ are admitted with seizures and seizures recur in $60 \%$ during admission (56). In other models, irreversible neuron damage is described after prolonged seizure activity; within days, edema is recognized on MRI (57) but overtime, this is replaced by local atrophy and gliosis (58). However, there is no consensus as to whether seizures cause the brain injury or are a manifestation of an injured brain $(59,60)$. Thus, although prophylactic anticonvulsants in traumatic brain injury (TBI) prevented imme- 

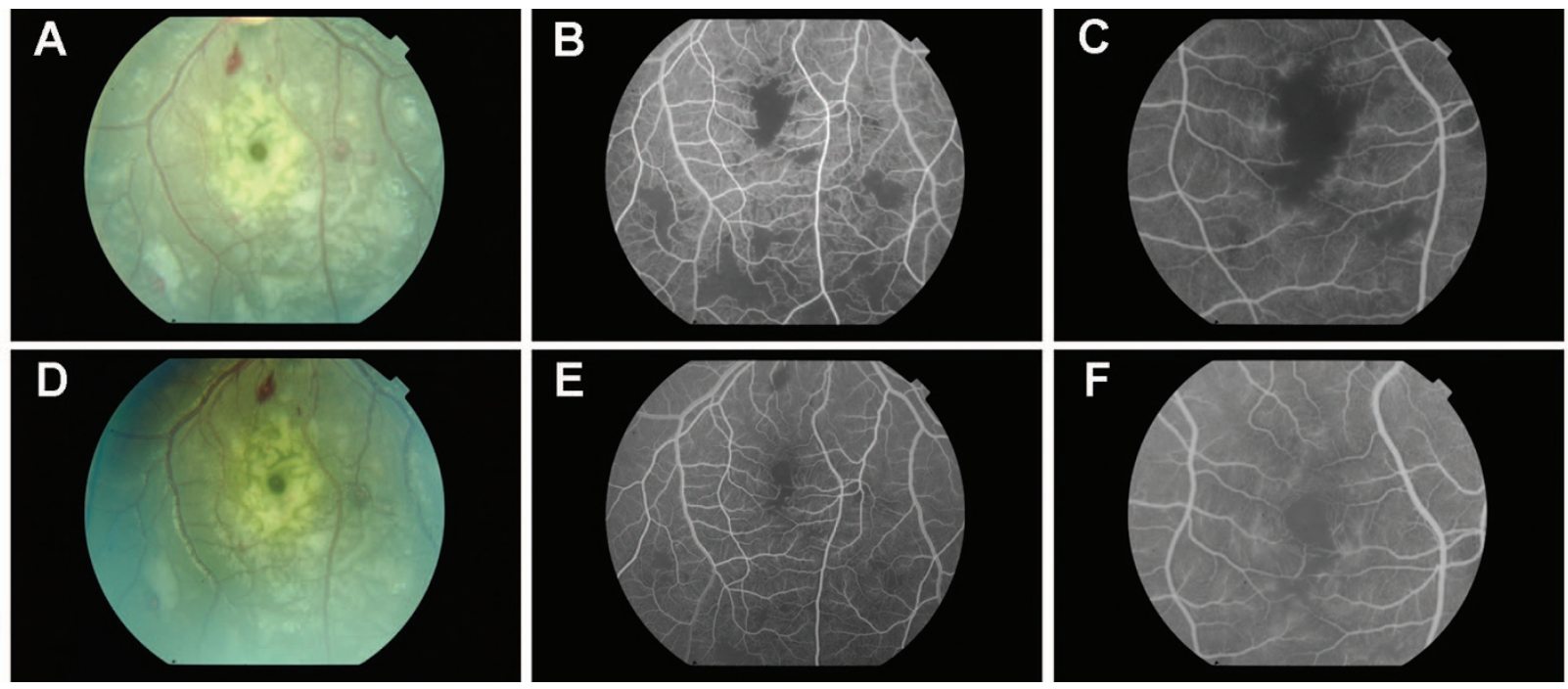

Figure 2. Retinal changes and fluorescein angiography in a child with cerebral malaria. Day 1 (admission is d 0): (A) Color fundus photograph of a child with cerebral malaria; multiple retinal hemorrhages are visible. No major change from admission. $(B)$ Fluorescein angiography shows multiple areas of retinal nonperfusion. These are more clearly delineated than on $\mathrm{d} 0$ (admission). (C) At higher magnification and later in the angiography run, there is some mild leakage round the border of the perfused and nonperfused zones. The leakage may suggest dysfunction of the blood-retina barrier. Day 3 of coma: $(D)$ There is little change in appearance when compared with d 1. (E) But there is substantial recovery in areas of nonperfusion. $(F)$ At higher magnification and later in the angiography run, leakage of fluorescein from reperfused capillaries, and capillaries previously on the border of nonperfusion is still observed. Photographs courtesy of Dr. Nicholas Beare—Royal Liverpool University Hospital and the Wellcome Trust—Liverpool School of Hygiene and Tropical Medicine Program in Malawi.

diate seizure recurrence, they did not reduce the risk of subsequent epilepsy (61). Similarly, high-dose prophylactic Phenobarbital in children with cerebral malaria significantly reduced seizure recurrences (62) but did not improve cognitive outcome (63). However, in this study, prophylactic Phenobarbital was associated with increased mortality (from respiratory depression) and the cognitive outcome study included only half of the original cohort. The likely scenario is that brain injury is caused by the seizure initiating noxious agent. Prolonged seizures may worsen this injury and setup a vicious circle of neural injury and more seizures.

\section{Depth, Duration, and Cause of Coma}

It has been suggested that cerebral malaria is not a single homogenous syndrome rather four distinct groups: a prolonged postictal state, covert status epilepticus, severe metabolic derangement, and a primary neurological syndrome (64). The fifth group may be patients with false cerebral malaria in whom coma has other causes and parasitemia is incidental (8).

Patients with prolonged postictal state have coma secondary to seizures, regain consciousness within $6 \mathrm{~h}$, and have a good neurological recovery. Although the seizures are different from simple febrile seizures, the same risk factors may be at play. On the other hand, those with convert status epilepticus present with coma after prolonged seizures. The physical signs of seizure activity are often so minimal that they may not be recognized. Failure to detect the state can be disastrous because these patients are hypoxic and hypercarbic from hypoventilation and at risk of aspiration. The neurocognitive outcome may depend on how long the seizures have lasted.

Patients with severe metabolic derangement may regain consciousness a few hours after resuscitation. Impaired con- sciousness is a secondary phenomenon to an unfavorable environment. Again, prolonged periods of either hypoglycemia or acidosis may cause neuronal dysfunction or death and, outcome may depend on duration of exposure among survivors.

Death and neurological sequelae may arise from different mechanisms. In Gambian children, neurological sequelae were associated with repeated seizures and with deep and prolonged coma, whereas death was associated with hypoglycemia and acidosis suggesting that most early deaths in cerebral malaria may result from an overwhelming metabolic derangement (65). Early correction of these derangements may buy time for definitive treatment. Recent phase II trials of albumin as a resuscitative fluid have supported this assertion (66) and have led to the on going Fluid Expansion as Supportive Therapy trial for very sick children in several African hospitals.

Patients with a primary neurological syndrome present with seizures often without severe metabolic disturbances and have the worst neurocognitive outcome. They are not severely anemic, and coma persists for $24-48 \mathrm{~h}$ well beyond the resolution of seizures. Intracranial hypertension is common. Coma may be a primary consequence of intracranial sequestration of malaria parasites.

\section{Pathogenesis of Some Specific Impairment}

Cognitive sequelae. In a prospective study, long-term cognitive impairment was described in $25 \%$ of children (18). Retrospective studies had documented rates of $14-24 \%$ $(17,67)$. Risk factors for cognitive impairment included hypoglycemia, seizures, depth and duration of coma, and hyporeflexia $(18,23,67,68)$. Only one study has investigated the immunopathogenesis of cognitive impairment (29). In this 
study, serum levels of multiple cytokines and chemokines did not correlate with impairment 6 mo after discharge, but CSF levels of TNF correlated with working memory and attention suggesting that elevated levels of CNS TNF adversely affects long-term cognitive outcome. The paucity of literature on risk factors for cognitive impairment highlights the need for additional studies in this area.

Speech and language impairment. Cerebral malaria is a leading cause of acquired language disorder in the tropics; $11.8 \%$ of surviving children have deficits especially in vocabulary, receptive and expressive speech, word finding, and phonology. Most deficits are observed in a subgroup of children some of whom have concurrent impairments in nonverbal functioning, memory, or attention (69). The pathogenesis is poorly understood; it is unclear whether the language deficits are part of a global injury or severe malaria causes injury to specific language centers. Studies with functional imaging may be useful in delineating pathogenesis.

Epilepsy. Epilepsy develops in $\sim 10 \%$ of exposed children months to years after exposure (16), and the cumulative incidence increases with time (70). Although seizures in cerebral malaria occur in the context of a febrile illness and many have complex features, temporal lobe epilepsy is uncommon; instead, mostly generalized tonic-clonic and secondarily generalized seizures are observed (71). The pathogenesis of epilepsy is poorly understood although it may be a consequence of focal hypoxic/ischemic injury in border-zone areas of cerebral circulation $(56,72)$ or global ischemic injury $(48,72)$.

Recent concepts of epileptogenesis hypothesize that in patients exposed to brain injury, multiple areas of hyperexcitable networks each with different seizure probability and independent discharges may develop in the brain. Clinical seizures may develop when these discharges coalesce and involve more of the surrounding normal brain (73). This concept has been studied in animal models and in patients with intractable temporal lobe epilepsy in whom there is extensive neural cell loss, gliosis, axonal sprouting, and formation of new synapses in the hippocampus. Surviving neurons and glia express genes encoding ion channels and receptors-changes thought to be responsible for the altered physiologic features of the injured region (74). If the concept is true, in cerebral malaria, hypoxic/ ischemic neural injury in areas of nonperfusion may be the casual mechanism.

Behavior and neuropsychiatric disorders. In children, behavior problems include inattention, impulsiveness and hyperactivity, conduct disorders, and impaired social development. Obsessive, self-injurious and destructive behaviors are also observed (17,55) (Richard Idro, personal observations). Symptoms develop 1-4 mo after exposure and the pathogenesis is unclear. In adults, the postmalaria neurological syndrome (Table 1) develops after parasites have been cleared (75). The pathogenesis is also unclear. Prospective studies are needed to describe these problems clearly, examine pathogenesis, and initiate therapeutic studies.

In summary, cytoadherence and sequestration of pRBCs in cerebral microvasculature initiate local endothelial injury and apoptosis, inflammation, BBB dysfunction, brain swelling, and intracranial hypertension. Sequestration impairs local perfusion and may cause hypoxic injury. The noxious insults and epileptogenic parasites cause seizures which in turn may setup a vicious circle of brain injury and more seizures. Severe metabolic derangement may worsen the injury. The extent of brain injury may depend on causation of coma, degree of microvascular obstruction, and inflammatory response; duration of exposure, presence of concurrent complications such as shock, and availability and speed of interventions. To improve outcome, different mechanisms of injury may require separate interventions.

\section{STRATEGIES FOR IMPROVED NEUROCOGNTIVE OUTCOME}

\section{Neuroprotective and Adjuvant Therapies}

Brain injury after the exposure to noxious insult evolves over hours or days. This has raised the possibility that early intervention may limit injury. However, most neuroprotective interventions in man, particularly in TBI, have been disappointing. A poor understanding of pathophysiological mechanisms, properties of compounds used (e.g. appropriate therapeutic time window), patient selection, or choice of endpoints have been blamed for the failure (76). Studies in cerebral malaria have also been disappointing. These included interventions targeting elements of pathogenesis and risk factors for brain injury. Thus, there have been trials of steroids, immunoglobulin, acetyl salicylic acid, heparin, anti-TNF agents, mannitol, iron chelation, micronutrients, and prophylactic anticonvulsants. Because prophylactic Phenobarbital was associated with respiratory depression (62), there is an ongoing trial evaluating a less respiratory depressant prophylactic anticonvulsant, fosphenytoin.

More recent studies have examined the possibility of preventing endothelial injury or reversing rossetting and improving blood flow. In a murine model, administration of a lowmolecular weight thiol, the B5 complex provitamin pantethine, prevented the development of cerebral malaria. Pantethine seemed to offer this protection by down-regulating platelet reactivity and release of microparticles from the activated endothelium. Attenuation of these processes left an intact BBB integrity (77). In another study, Glatiramer acetate, an immunomodulatory agent, was associated with a lower risk of cerebral malaria in treated animals (78). In both cases, human trials are awaited.

Two different anti-apoptotic approaches-treatment with $\mathrm{z}-\mathrm{VAD}$ (a pan-caspase inhibitor) and overexpression of $\mathrm{Bcl}-2$ (a gene that prevents the release of apoptotic mediators from the mitochondria) - did not reduce cerebral malaria mortality in mice (79). However, the cytokine erythropoietin, which has anti-apoptotic, anti-inflammatory, vasodilating and neurotrophic properties, and widespread receptors in the brain, has shown greater promise. It crosses the $\mathrm{BBB}$, and local synthesis is increased during hypoxia. Erythropoietin provided neuroprotection in animal models of TBI, infectious encephalopathy, and hypoxic ischemic encephalopathy (80) and offered protection against endothelial injury in the heart, causing NO-mediated coronary vasodilatation, increasing blood flow, 
enhancing repair, and reducing apoptosis (81). In adults with stroke, high-dose erythropoietin reduced brain-infarct size and improved functional outcome (82). In mice with cerebral malaria, high-dose erythropoietin reduced mortality by $40-$ $90 \%$, (reviewed in Ref. 83) and in children, plasma levels $>200 \mu / \mathrm{L}$ were associated with $\sim 80 \%$ less risk of sequelae (84). A phase I study of erythropoietin, $1500 \mu / \mathrm{kg}$, in children with cerebral malaria was recently concluded without any major concerns about the safety (85).

Heparan sulfate on endothelial cells mediates binding of pRBCs via DBL1 alpha domain of PfEMP1 (86). Interfering with this binding can potentially reduce parasite sequestration. Earlier studies of heparin and acetyl salicylic acid were not continued because they either failed to demonstrate sufficient evidence of benefit or because of toxicity. However, more recently, compounds with less anticoagulant effects have been developed. A Swedish group has recently completed a phase I trial of DFO2, a modified form of heparin with minimal anticoagulant activity, and plan to take this to phase II studies (Anna Vogt, personal communication).

Clearly, a poor understanding of pathogenesis is a major hindrance to progress in cerebral malaria research. MRI offers a way out including a noninvasive study of the structural, metabolic, biochemical, and functional features of the brain in vivo (87). A combination of time of flight angiography and diffusion-weighted imaging can describe obstruction to flow and the effects of obstruction in distal areas. Cerebral blood flow can be measured using arterial spin labeling while functional MRI can be used to describe neural activity in coma. In addition, proton MR spectroscopy can be used to measure levels of substrates and metabolites.

\section{Rehabilitation}

Because of the high mortality associated with cerebral malaria, few studies have focused on rehabilitation for children with sequelae. There are no guidelines to assess impairments or guide rehabilitation (88). With declining child mortality in the region and the growing number of exposed and therefore potentially impaired children, systems are needed to detect impairments and to develop and implement rehabilitation. Particular areas include physical and occupational therapy, behavior and speech therapy, cognitive rehabilitation, and hearing aids. A preliminary study of cognitive rehabilitation using a computerized program has demonstrated improved neuropsychological and behavioral outcomes in exposed children suggesting that similar interventions are possible (89).

\section{CONCLUSION}

Cerebral malaria causes brain injury in an unacceptable number of children. It is not a single and discrete syndrome; in different patients, coma develops through multiple mechanisms and there are several mechanisms of brain injury. Combinations of adjuvant therapies targeting specific mechanisms of brain injury may be needed to improve neurocognitive outcome. In the meantime, MR imaging may provide important insights into pathogenesis.

\section{REFERENCES}

1. Snow RW, Guerra CA, Noor AM, Myint HY, Hay SI 2005 The global distribution of clinical episodes of Plasmodium falciparum malaria. Nature 434:214-217

2. Breman JG 2001 The ears of the hippopotamus: manifestations, determinants, and estimates of the malaria burden. Am J Trop Med Hyg 64:1-11

3. Okiro EA, Hay SI, Gikandi PW, Sharif SK, Noor AM, Peshu N, Marsh K, Snow RW 2007 The decline in paediatric malaria admissions on the coast of Kenya. Malar J 6:151

4. Nyarango PM, Gebremeskel T, Mebrahtu G, Mufunda J, Abdulmumini U, Ogbamariam A, Kosia A, Gebremichael A, Gunawardena D, Ghebrat Y, Okbaldet Y 2006 A steep decline of malaria morbidity and mortality trends in Eritrea between 2000 and 2004: the effect of combination of control methods. Malar J 5:33

5. Idro R, Jenkins NE, Newton CR 2005 Pathogenesis, clinical features, and neurological outcome of cerebral malaria. Lancet Neurol 4:827-840

6. Newton CR, Hien TT, White N 2000 Cerebral malaria. J Neurol Neurosurg Psychiatry 69:433-441

7. World Health Organization 2000 Severe falciparum malaria. World Health Organization, Communicable Diseases Cluster. Trans R Soc Trop Med Hyg 94:S1-S90

8. Taylor TE, Fu WJ, Carr RA, Whitten RO, Mueller JS, Fosiko NG, Lewallen S, Liomba NG, Molyneux ME 2004 Differentiating the pathologies of cerebral malaria by postmortem parasite counts. Nat Med 10:143-145

9. Beare NA, Taylor TE, Harding SP, Lewallen S, Molyneux ME 2006 Malarial retinopathy: a newly established diagnostic sign in severe malaria. Am J Trop Med Hyg 75:790-797

10. Clark IA, Alleva LM 2009 Is human malarial coma caused, or merely deepened, by sequestration? Trends Parasitol 25:314-318

11. Dondorp A, Nosten F, Stepniewska K, Day N, White N 2005 Artesunate versus quinine for treatment of severe falciparum malaria: a randomised trial. Lancet 366:717-725

12. Muntendam AH, Jaffar S, Bleichrodt N, van Hensbroek MB 1996 Absence of neuropsychological sequelae following cerebral malaria in Gambian children. Trans R Soc Trop Med Hyg 90:391-394

13. Newton CR, Krishna S 1998 Severe falciparum malaria in children: current understanding of pathophysiology and supportive treatment. Pharmacol Ther 79:1-53

14. Brewster DR, Kwiatkowski D, White NJ 1990 Neurological sequelae of cerebral malaria in children. Lancet 336:1039-1043

15. van Hensbroek MB, Palmer A, Jaffar S, Schneider G, Kwiatkowski D 1997 Residual neurologic sequelae after childhood cerebral malaria. J Pediatr 131:125-129

16. Ngoungou EB, Preux PM 2008 Cerebral malaria and epilepsy. Epilepsia 49:19-24

17. Carter JA, Mung'ala-Odera V, Neville BG, Murira G, Mturi N, Musumba C, Newton CR 2005 Persistent neurocognitive impairments associated with severe falciparum malaria in Kenyan children. J Neurol Neurosurg Psychiatry 76:476-481

18. John CC, Bangirana P, Byarugaba J, Opoka RO, Idro R, Jurek AM, Wu B, Boivin MJ 2008 Cerebral malaria in children is associated with long-term cognitive impairment. Pediatrics 122:e92-e99

19. White NJ, Turner GD, Medana IM, Dondorp AM, Day NP 2010 The murine cerebral malaria phenomenon. Trends Parasitol 26:11-15

20. MacPherson GG, Warrell MJ, White NJ, Looareesuwan S, Warrell DA 1985 Human cerebral malaria. A quantitative ultrastructural analysis of parasitized erythrocyte sequestration. Am J Pathol 119:385-401

21. Newbold C, Craig A, Kyes S, Rowe A, Fernandez-Reyes D, Fagan T 1999 Cytoadherence, pathogenesis and the infected red cell surface in Plasmodium falciparum. Int J Parasitol 29:927-937

22. Dondorp AM, Pongponratn E, White NJ 2004 Reduced microcirculatory flow in severe falciparum malaria: pathophysiology and electron-microscopic pathology. Acta Trop 89:309-317

23. Idro R, Carter JA, Fegan G, Neville BG, Newton CR 2006 Risk factors for persisting neurological and cognitive impairments following cerebral malaria. Arch Dis Child 91:142-148

24. Newton CR, Crawley J, Sowumni A, Waruiru C, Mwangi I, English M, Murphy S, Winstanley PA, Marsh K, Kirkham FJ 1997 Intracranial hypertension in Africans with cerebral malaria. Arch Dis Child 76:219-226

25. Hunt NH, Grau GE 2003 Cytokines: accelerators and brakes in the pathogenesis of cerebral malaria. Trends Immunol 24:491-499

26. Di Perri G, Di Perri IG, Monteiro GB, Bonora S, Hennig C, Cassatella M, Micciolo R, Vento S, Dusi S, Bassetti D, Concia E 1995 Pentoxifylline as a supportive agent in the treatment of cerebral malaria in children. J Infect Dis 171:1317-1322

27. Looareesuwan S, Wilairatana P, Vannaphan S, Wanaratana V, Wenisch C, Aikawa M, Brittenham G, Graninger W, Wernsdorfer WH 1998 Pentoxifylline as an ancillary treatment for severe falciparum malaria in Thailand. Am J Trop Med Hyg 58:348-353

28. van Hensbroek MB, Palmer A, Onyiorah E, Schneider G, Jaffar S, Dolan G, Memming H, Frenkel J, Enwere G, Bennett S, Kwiatkowski D, Greenwood B 1996 The effect of a monoclonal antibody to tumor necrosis factor on survival from childhood cerebral malaria. J Infect Dis 174:1091-1097

29. John CC, Panoskaltsis-Mortari A, Opoka RO, Park GS, Orchard PJ, Jurek AM, Idro R, Byarugaba J, Boivin MJ 2008 Cerebrospinal fluid cytokine levels and cognitive impairment in cerebral malaria. Am J Trop Med Hyg 78:198-205

30. John CC, Opika-Opoka R, Byarugaba J, Idro R, Boivin MJ 2006 Low levels of RANTES are associated with mortality in children with cerebral malaria. J Infect Dis 194:837-845

31. Anstey NM, Weinberg JB, Hassanali MY, Mwaikambo ED, Manyenga D, Misukonis MA, Arnelle DR, Hollis D, McDonald MI, Granger DL 1996 Nitric oxide in Tanzanian children with malaria: inverse relationship between malaria severity and nitric oxide production/nitric oxide synthase type 2 expression. J Exp Med 184:557-567

32. Cramer JP, Nussler AK, Ehrhardt S, Burkhardt J, Otchwemah RN, Zanger P, Dietz E, Gellert S, Bienzle U, Mockenhaupt FP 2005 Age-dependent effect of plasma nitric 
oxide on parasite density in Ghanaian children with severe malaria. Trop Med Int Health 10:672-680

33. Clark IA, Rockett KA, Cowden WB 1992 Possible central role of nitric oxide in conditions clinically similar to cerebral malaria. Lancet 340:894-896

34. Dobbie M, Crawley J, Waruiru C, Marsh K, Surtees R 2000 Cerebrospinal fluid studies in children with cerebral malaria: an excitotoxic mechanism? Am J Trop Med Hyg 62:284-290

35. Medana IM, Hien TT, Day NP, Phu NH, Mai NT, Chu'ong LV, Chau TT, Taylor A, Salahifar H, Stocker R, Smythe G, Turner GD, Farrar J, White NJ, Hunt NH 2002 The clinical significance of cerebrospinal fluid levels of kynurenine pathway metabolites and lactate in severe malaria. J Infect Dis 185:650-656

36. Touré FS, Ouwe-Missi-Oukem-Boyer O, Bisvigou U, Mousa O, Rogier C, Pino P, Mazier D, Bisser S 2008 Apoptosis: a potential triggering mechanism of neurological manifestation in Plasmodium falciparum malaria. Parasite Immunol 30:47-51

37. Combes V, Taylor TE, Juhan-Vague I, Mege JL, Mwenechanya J, Tembo M, Grau GE, Molyneux ME 2004 Circulating endothelial microparticles in Malawian children with severe falciparum malaria complicated with coma. JAMA 291:2542-2544

38. Combes V, Coltel N, Faille D, Wassmer SC, Grau GE 2006 Cerebral malaria: role of microparticles and platelets in alterations of the blood-brain barrier. Int J Parasitol 36:541-546

39. Gyan B, Goka BQ, Adjei GO, Tetteh JK, Kusi KA, Aikins A, Dodoo D, Lesser ML, Sison CP, Das S, Howard ME, Milbank E, Fischer K, Rafii S, Jin D, Golightly LM 2009 Cerebral malaria is associated with low levels of circulating endothelial progenitor cells in African children. Am J Trop Med Hyg 80:541-546

40. Lovegrove FE, Tangpukdee N, Opoka RO, Lafferty EI, Rajwans N, Hawkes M, Krudsood S, Looareesuwan S, John CC, Liles WC, Kain KC 2009 Serum angiopoietin-1 and -2 levels discriminate cerebral malaria from uncomplicated malaria and predict clinical outcome in African children. PLoS One 4:e4912

41. Lackner P, Burger C, Pfaller K, Heussler V, Helbok R, Morandell M, Broessner G, Tannich E, Schmutzhard E, Beer R 2007 Apoptosis in experimental cerebral malaria: spatial profile of cleaved caspase-3 and ultrastructural alterations in different disease stages. Neuropathol Appl Neurobiol 33:560-571

42. Pino P, Vouldoukis I, Kolb JP, Mahmoudi N, Desportes-Livage I, Bricaire F, Danis M, Dugas B, Mazier D 2003 Plasmodium falciparum - infected erythrocyte adhesion induces caspase activation and apoptosis in human endothelial cells. J Infect Dis 187:1283-1290

43. Potter S, Chan-Ling T, Ball HJ, Mansour H, Mitchell A, Maluish L, Hunt NH 2006 Perforin mediated apoptosis of cerebral endothelial cells during experimental cerebral malaria. Int J Parasitol 36:485-496

44. Medana IM, Day NP, Hien TT, Mai NT, Bethell D, Phu NH, Farrar J, Esiri MM, White NJ, Turner GD 2002 Axonal injury in cerebral malaria. Am J Pathol 160:655-666

45. Medana IM, Idro R, Newton CR 2007 Axonal and astrocyte injury markers in the cerebrospinal fluid of Kenyan children with severe malaria. J Neurol Sci 258:93-98

46. Brown H, Hien TT, Day N, Mai NT, Chuong LV, Chau TT, Loc PP, Phu NH, Bethell D, Farrar J, Gatter K, White N, Turner G 1999 Evidence of blood-brain barrier dysfunction in human cerebral malaria. Neuropathol Appl Neurobiol 25:331-340

47. Brown H, Rogerson S, Taylor T, Tembo M, Mwenechanya J, Molyneux M, Turner G 2001 Blood-brain barrier function in cerebral malaria in Malawian children. Am J Trop Med Hyg 64:207-213

48. Newton CR, Peshu N, Kendall B, Kirkham FJ, Sowunmi A, Waruiru C, Mwangi I, Murphy SA, Marsh K 1994 Brain swelling and ischaemia in Kenyans with cerebral malaria. Arch Dis Child 70:281-287

49. Walker O, Salako LA, Sowunmi A, Thomas JO, Sodeine O, Bondi FS 1992 Prognostic risk factors and post mortem findings in cerebral malaria in children. Trans R Soc Trop Med Hyg 86:491-493

50. Clavier N, Rahimy C, Falanga P, Ayivi B, Payen D 1999 No evidence for cerebral hypoperfusion during cerebral malaria. Crit Care Med 27:628-632

51. Beare NA, Harding SP, Taylor TE, Lewallen S, Molyneux ME 2009 Perfusion abnormalities in children with cerebral malaria and malarial retinopathy. J Infect Dis 199:263-271

52. Lochhead J, Movaffaghy A, Falsini B, Harding S, Riva C, Molyneux M 2010 The effects of hypoxia on the ERG in paediatric cerebral malaria. Eye (Lond) 24:259-264

53. Maude RJ, Dondorp AM, Abu Sayeed A, Day NP, White NJ, Beare NA 2009 The eye in cerebral malaria: what can it teach us? Trans R Soc Trop Med Hyg 103:661-664

54. Newton CR, Marsh K, Peshu N, Kirkham FJ 1996 Perturbations of cerebral hemodynamics in Kenyans with cerebral malaria. Pediatr Neurol 15:41-49

55. Idro R, Ndiritu M, Ogutu B, Mithwani S, Maitland K, Berkley J, Crawley J, Fegan G, Bauni E, Peshu N, Marsh K, Neville B, Newton C 2007 Burden, features, and outcome of neurological involvement in acute falciparum malaria in Kenyan children. JAMA 297:2232-2240

56. Crawley J, Smith S, Kirkham F, Muthinji P, Waruiru C, Marsh K 1996 Seizures and status epilepticus in childhood cerebral malaria. QJM 89:591-597

57. Scott RC, King MD, Gadian DG, Neville BG, Connelly A 2003 Hippocampal abnormalities after prolonged febrile convulsion: a longitudinal MRI study. Brain 126:2551-2557

58. Sokol DK, Demyer WE, Edwards-Brown M, Sanders S, Garg B 2003 From swelling to sclerosis: acute change in mesial hippocampus after prolonged febrile seizure. Seizure 12:237-240

59. Holtkamp M, Schuchmann S, Gottschalk S, Meierkord H 2004 Recurrent seizures do not cause hippocampal damage. J Neurol 251:458-463

60. Verity CM 1998 Do seizures damage the brain? The epidemiological evidence. Arch Dis Child 78:78-84

61. Temkin NR 2001 Antiepileptogenesis and seizure prevention trials with antiepileptic drugs: meta-analysis of controlled trials. Epilepsia 42:515-524
62. Crawley J, Waruiru C, Mithwani S, Mwangi I, Watkins W, Ouma D, Winstanley P, Peto T, Marsh K 2000 Effect of phenobarbital on seizure frequency and mortality in childhood cerebral malaria: a randomised, controlled intervention study. Lancet 355:701-706

63. Abubakar A, Van De Vijver FJ, Mithwani S, Obiero E, Lewa N, Kenga S, Katana K, Holding P 2007 Assessing developmental outcomes in children from Kilifi, Kenya, following prophylaxis for seizures in cerebral malaria. J Health Psychol $12: 417-430$

64. Marsh K, English M, Crawley J, Peshu N 1996 The pathogenesis of severe malaria in African children. Ann Trop Med Parasitol 90:395-402

65. Jaffar S, Van Hensbroek MB, Palmer A, Schneider G, Greenwood B 1997 Predictors of a fatal outcome following childhood cerebral malaria. Am J Trop Med Hyg 57:20-24

66. Akech S, Gwer S, Idro R, Fegan G, Eziefula AC, Newton CR, Levin M, Maitland K 2006 Volume expansion with albumin compared to gelofusine in children with severe malaria: results of a controlled trial. PLoS Clin Trials 1:e21

67. Holding PA, Stevenson J, Peshu N, Marsh K 1999 Cognitive sequelae of severe malaria with impaired consciousness. Trans R Soc Trop Med Hyg 93:529-534

68. Kihara M, Carter JA, Holding P, Vargha-Khadem F, Scott RC, Idro R, Fegan G, de Haan M, Neville BG, Newton CR 2009 Impaired everyday memory associated with encephalopathy of severe malaria: the role of seizures and hippocampal damage. Malar J 8:273

69. Carter JA, Lees JA, Gona JK, Murira G, Rimba K, Neville BG, Newton CR 2006 Severe falciparum malaria and acquired childhood language disorder. Dev Med Child Neurol 48:51-57

70. Opoka RO, Bangirana P, Boivin MJ, John CC, Byarugaba J 2009 Seizure activity and neurological sequelae in Ugandan children who have survived an episode of cerebral malaria. Afr Health Sci 9:75-81

71. Carter JA, Neville BG, White S, Ross AJ, Otieno G, Mturi N, Musumba C, Newton CR 2004 Increased prevalence of epilepsy associated with severe falciparum malaria in children. Epilepsia 45:978-981

72. Potchen MJ, Birbeck GL, Demarco JK, Kampondeni SD, Beare N, Molyneux ME, Taylor TE 2010 Neuroimaging findings in children with retinopathy-confirmed cerebral malaria. Eur J Radiol 74:262-268

73. Dichter MA 2009 Emerging concepts in the pathogenesis of epilepsy and epileptogenesis. Arch Neurol 66:443-447

74. Bernard C, Anderson A, Becker A, Poolos NP, Beck H, Johnston D 2004 Acquired dendritic channelopathy in temporal lobe epilepsy. Science 305:532-535

75. Falchook GS, Malone CM, Upton S, Shandera WX 2003 Postmalaria neurological syndrome after treatment of Plasmodium falciparum malaria in the United States. Clin Infect Dis 37:e22-e24

76. Tolias CM, Bullock MR 2004 Critical appraisal of neuroprotection trials in head injury: what have we learned? NeuroRx 1:71-79

77. Penet MF, Abou-Hamdan M, Coltel N, Cornille E, Grau GE, de Reggi M, Gharib B 2008 Protection against cerebral malaria by the low-molecular-weight thiol pantethine. Proc Natl Acad Sci USA 105:1321-1326

78. Lackner P, Part A, Burger C, Dietmann A, Broessner G, Helbok R, Reindl M, Schmutzhard E, Beer R 2009 Glatiramer acetate reduces the risk for experimental cerebral malaria: a pilot study. Malar J 8:36

79. Helmers AJ, Lovegrove FE, Harlan JM, Kain KC, Liles WC 2008 Failure of two distinct anti-apoptotic approaches to reduce mortality in experimental cerebral malaria. Am J Trop Med Hyg 79:823-825

80. Grasso G, Sfacteria A, Cerami A, Brines M 2004 Erythropoietin as a tissueprotective cytokine in brain injury: what do we know and where do we go? Neuroscientist 10:93-98

81. Mihov D, Bogdanov N, Grenacher B, Gassmann M, Zünd G, Bogdanova A, Tavakoli R 2009 Erythropoietin protects from reperfusion-induced myocardial injury by enhancing coronary endothelial nitric oxide production. Eur J Cardiothorac Surg 35:839-846

82. Ehrenreich H, Hasselblatt M, Dembowski C, Cepek L, Lewczuk P, Stiefel M, Rustenbeck HH, Breiter N, Jacob S, Knerlich F, Bohn M, Poser W, Ruther E, Kochen M, Gefeller O, Gleiter C, Wessel TC, De Ryck M, Itri L, Prange H, Cerami A, Brines M, Siren AL 2002 Erythropoietin therapy for acute stroke is both safe and beneficial. Mol Med 8:495-505

83. Casals-Pascual C, Idro R, Picot S, Roberts DJ, Newton CR 2009 Can erythropoietin be used to prevent brain damage in cerebral malaria? Trends Parasitol 25:30-36

84. Casals-Pascual C, Idro R, Gicheru N, Gwer S, Kitsao B, Gitau E, Mwakesi R, Roberts DJ, Newton CR 2008 High levels of erythropoietin are associated with protection against neurological sequelae in African children with cerebral malaria. Proc Natl Acad Sci USA 105:2634-2639

85. Picot S, Bienvenu AL, Konate S, Sissoko S, Barry A, Diarra E, Bamba K, Djimde A, Doumbo OK 2009 Safety of epoietin beta-quinine drug combination in children with cerebral malaria in Mali. Malar J 8:169

86. Vogt AM, Barragan A, Chen Q, Kironde F, Spillmann D, Wahlgren M 2003 Heparan sulfate on endothelial cells mediates the binding of Plasmodium falciparum-infected erythrocytes via the DBL1alpha domain of PfEMP1. Blood 101:2405-2411

87. Looareesuwan S, Laothamatas J, Brown TR, Brittenham GM 2009 Cerebral malaria: a new way forward with magnetic resonance imaging (MRI). Am J Trop Med Hyg $81: 545-547$

88. Bangirana P, Idro R, John CC, Boivin MJ 2006 Rehabilitation for cognitive impairments after cerebral malaria in African children: strategies and limitations. Trop Med Int Health 11:1341-1349

89. Bangirana P, Giordani B, John CC, Page C, Opoka RO, Boivin MJ 2009 Immediate neuropsychological and behavioral benefits of computerized cognitive rehabilitation in Ugandan pediatric cerebral malaria survivors. J Dev Behav Pediatr 30:310-318 